\title{
The Vortex Aircooler System for Cutting Materials in Aerospace Industry
}

\author{
G.O. Belov ${ }^{1}$, S.S Dostovalova ${ }^{2}$, E. O. Barbonov², D.A. Uglanov², , P.A. Chertykovtsev² and R.A. \\ Panshin $^{2}$ \\ 1 - JSC «Salut», 20 km, Moskovskoeshosse, Samara, 443028, Russian Federation \\ 2 - Samara National Research University34, Moskovskoeshosse, Samara, 443086, Russian Federation
}

\begin{abstract}
In aerospace industry there is a situation, when it is not possible to use liquid cooling of cutting zone, because we have special material or special construction. How often in that case used air fluent, but it has some problems with life cycle tools, quality and cutting time. For solving these problems was use the vortex effect, it was open less than one hundred years ago. The unit for making vortex effect is could vortex tube.

It was done the design the vortex tube of air cooler system for cutting using some researching [1-5]. Some experimental dates gave verification. The construction was made by metal materials and now is using on JSC «Salut», Samara..
\end{abstract}

\section{INTRODUCTION}

Modern machining takes place in the presence of a standard lubricating coolant (coolant), which is fed directly into the cutting zone through the channels in the tool or external tubes. However, a large group of materials due to low corrosion resistance has to be treated with the use of special coolant, but it should be noted that in real mechanical production it is not always possible to stop the machine to replace the coolant. Taking into account the fact that all aerospace production is small-scale, frequent replacement of coolant is an economically inappropriate action. There is also a whole group of structural materials, the mechanical processing of which is carried out at all without the use of a lubricating cooling liquid. There are cases when the use of coolant must be abandoned not because of the properties of the material of the part, but because of the design itself. For example, drilling largesized sheet metal parts is carried out without the use of coolant, because in view of the large dimensions of the component, the liquid will not circulate in the machine as it should, but it will drain over the sheet metal into the non-working space, which is unacceptable. It is also worth noting that not all machines are equipped with a coolant supply system.

Traditionally, in these cases a jet of compressed air is used for cooling, the efficiency of which is several times smaller, which negatively affects the tool's durability, the quality of the surface being treated and the laboriousness of the machining. In order to partially remove these negative phenomena, it is proposed to use the vortex effect, which was discovered less than a hundred years ago. This phenomenon, realized in a special device called a vortex tube, allows the compressed gas flow to be

\footnotetext{
${ }^{a}$ Corresponding author: dmitry.uglanov@mail.ru
} 
divided into hot and cold [6]. We will feed the cold stream into the cutting zone, and we will transfer the hot stream to the periphery. Use in the design of the vortex tube is due to its reliability and simplicity of the device.

\section{CALCULATION OF THE MAIN PARAMETERS OF THE DEVICE}

The device for the countercurrent vortex tube is shown in Fig. 1. It shows the following elements - a tube 2 with a tangential supply of compressed air through the cochlea 1; one end of the tube is closed by a lid with a diaphragm 4 - a cold flow through it, and through the other end of the tube with the throttle 3 a hot stream emerges.

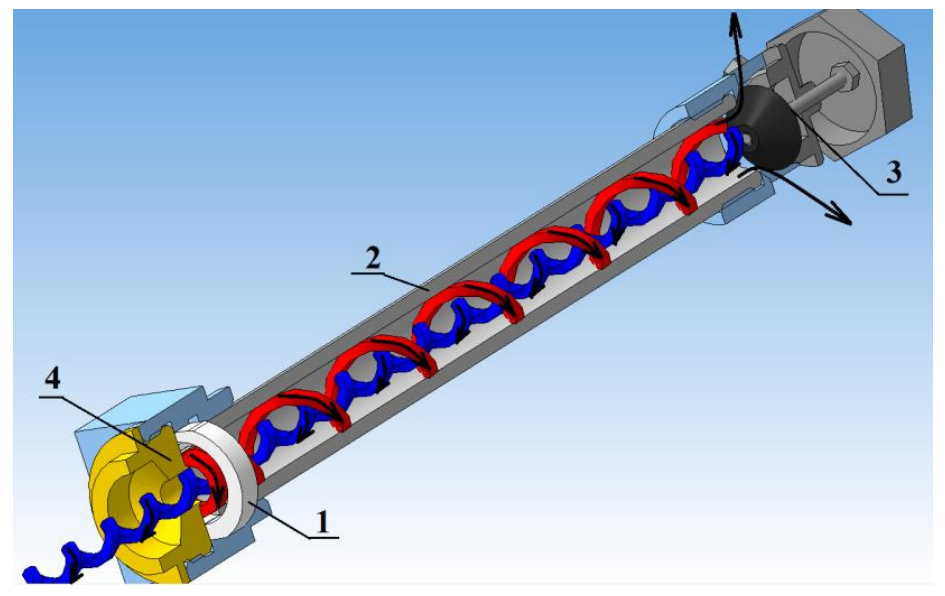

Figure 1.Arrangement of a countercurrent vortex tube.

Despite the relative simplicity of the tube device, the vortex effect is not fully understood. At the moment, the most accurate and logical description of the vortex effect for the countercurrent tube is provided by the "vortex interaction hypothesis". There are two vortices in the tube. The first "free", which displaces air through the throttle, the second "forced", acting in the axial direction and forcing air through the diaphragm. As a result of the intense turbulent interaction of these vortices, a cooled gas exits through the diaphragm, and a hot gas through the choke. [1]

There are a large number of papers, including [1-5,7], in which differential equations describing the processes of turbulent energy-mass exchange are presented. The numerical solution of these equations explains the processes qualitatively but does not show them quantitatively. It is also worth noting that the results of the turbulent energy-mass exchange simulation largely depend not only on the boundary conditions, but also on the methods for their solution. Because of the lack of a common opinion, not only the initial system of equations, but also the methods of solutions, we will have to abandon numerical calculations and turn to empirical calculation methods. Here it is worth noting that different researchers of the vortex effect proposed their own techniques, which, unfortunately, with the same initial data give different values of the geometric parameters of the device.

At the moment there is a large number of not only theoretical, but also experimental studies of the vortex effect. Using the volume of experimental data representing the influence of various factors on $\Delta T_{\mathrm{x}}$ (the difference in temperatures at the entrance to the tube and the temperature of the cold flow), the following experimental dependences of $\Delta T_{\mathrm{x}}$ on [2] were found:

- $\quad$ the area of the inlet nozzle $F_{n}$;

- $\quad$ vortex tube diameter $D_{T}$;

- the relative diameter of the diaphragm $\overline{D_{\mathrm{D}}}=\frac{D_{\mathrm{D}}}{D_{T}}$;

- $\quad$ air pressure in front of the vortex tube $p_{i n}$; 
- the ratio of the flow of the cold flow to the flow at the inlet to the tube $\mu$;

- tube length in calibers $\bar{L}=\frac{L}{D_{T}}$.

Having considered these characteristics, we can conclude that $\Delta T_{\mathrm{x}}$ is a function of 6 variables:

$$
\Delta T_{\mathrm{x}}=f\left(\bar{L} ; \mu ; p_{i n} ; D_{T} ; \overline{D_{\mathrm{D}}} ; F_{n}\right)
$$

Since the considered construction was tested only with a spiral inlet, and different nozzle areas were investigated on a tube of the same diameter, it is advisable to introduce instead of Fn the relative equivalent diameter of the nozzle inlet of the vortex tube:

$$
\overline{d_{\mathrm{eq}}}=\frac{\sqrt{\frac{4 \cdot F_{n}}{\pi}}}{D_{T}}
$$

Taking this into account, we rewrite the function $\Delta T_{\mathrm{x}}$ :

$$
\Delta T_{\mathrm{x}}=f\left(\bar{L} ; \mu ; p_{i n} ; D_{T} ; \overline{D_{\mathrm{D}}} ; \overline{d_{e q}}\right)
$$

Since the graphical dependencies considered are continuous functions (on the ranges studied), we expand the above function in a Taylor series. The Taylor series for a function of six variables takes the form:

$$
f\left(x_{1} ; \ldots x_{6}\right)=f\left(x_{01} ; \ldots x_{06}\right)+\lim _{n \rightarrow \infty} \sum_{n=1}^{n} \frac{1}{n !} *\left[d^{n}(f)\right]_{0}
$$

where $\left[d^{n}(f)\right]_{0}$-the total differential of the $n$-th order in a neighborhood $\left(x_{01} ; \ldots x_{06}\right)$.

We draw attention to the fact that from the graphical dependencies given in [2], we can define only partial derivatives of the nth order with respect to one variable. A complete differential of the first order contains only partial derivatives of the first order and can be easily determined, while the differentials, beginning with the second order, contain derivatives of several variables. By the property of the Taylor series, each subsequent order of the differential is less "weight" than the previous one, therefore, for approximate calculations, it is often limited to the first order. The last remark enables us to conclude that the effect of individual variables on a function is significantly higher than their mutual influence. Neglecting, therefore, partial derivatives with respect to several variables, we can rewrite (4) as:

$$
f\left(x_{1} ; \ldots x_{6}\right) \approx f\left(x_{01} ; \ldots x_{06}\right)+\sum_{j=1}^{6} \lim _{n \rightarrow \infty} \sum_{n=1}^{n} \frac{\left(x_{j}-x_{0 j}\right)^{n}}{n !} * \frac{\partial^{n} f}{\partial x_{j}^{n}}\left(x_{01} ; \ldots x_{06}\right)
$$

where $x_{1} \ldots x_{6}$ - variables, $x_{01} \ldots x_{06}$ - some meaning of these variables. For the expansion ( 3 ) in a series, according to the formula given for six variables, we choose well-traced values of the variables on the considered graphical dependencies (common point):

$$
\bar{L}_{0}=15 ; p_{\text {in_0 }}=0,5 \mathrm{M \Pi а} ; D_{T_{-} 0}=28 \mathrm{Mm} ; \overline{D_{\mathrm{D}_{-} 0}}=0,5 ; \mu_{0}=0,5 ; \overline{d_{\text {eq_o }}}=0,25
$$

Function Value $\Delta T_{\mathrm{x}}$ at these values is $38 \mathrm{~K}$.

Considering the graphical dependences $\Delta T_{\mathrm{x}}=f(\bar{L}) ; \Delta T_{\mathrm{x}}=f\left(p_{\text {in }}\right) ; \Delta T_{\mathrm{x}}=f\left(D_{T}\right)$ it can be noted that the approximating curves are linear in the range under consideration, and therefore all partial derivatives of these functions starting with the second order can be equated to zero. The functions $\Delta T_{\mathrm{x}}=f\left(\overline{D_{\mathrm{D}}}\right), \Delta T_{\mathrm{x}}=f(\mu)$ are reliably approximated by a second-order polynomial function, so the derivatives of these functions starting with $\mathrm{n}=3$ equate to zero. The graphical dependence $\Delta T_{\mathrm{x}}=$ $f\left(\overline{d_{\text {eq }}}\right)$ is more complex, for its reliable approximation in the range of values used a third-order polynomial function is used, thus the fourth and subsequent orders of this function are equated to zero. In view of the foregoing, expanding (3) in a series (5) we obtain: 


$$
\begin{gathered}
\Delta \mathrm{Tx} \approx a+b_{1}\left(\bar{L}-c_{1}\right)+b_{2}\left(p_{i n}-c_{2}\right)+b_{3}\left(D_{\mathrm{T}}-c_{3}\right)+b_{4}\left(\overline{D_{\mathrm{D}}}-c_{4}\right)+b_{5}\left(\overline{D_{\mathrm{D}}}-c_{4}\right)^{2}+ \\
b_{6}\left(\mu-c_{5}\right)+b_{7}\left(\mu-c_{5}\right)^{2}+b_{8}\left(\overline{d_{\mathrm{eq}}}-c_{6}\right)+b_{9}\left(\overline{d_{\mathrm{eq}}}-c_{6}\right)^{2}+b_{10}\left(\overline{d_{\mathrm{eq}}}-c_{6}\right)^{3},
\end{gathered}
$$

where $a=\Delta T_{\mathrm{x}_{0} 0}=38 \mathrm{~K}$;

$b_{1} \ldots b_{10}$ - values of advisory partial derivatives taking factorial into account;

$\mathrm{c}_{1} \ldots \mathrm{c}_{6}-$ the corresponding values of the variables (6).

Values $b_{1} \ldots b_{10}$ were obtained from the experimental data [2] by means of a PC and are summarized in Table 1.

Table 1. Values of the coefficients a, $b_{1} \ldots b_{10}, c_{1} \ldots c_{6}$.

\begin{tabular}{|c|c|c|c|c|c|c|c|c|c|c|}
\hline $\mathrm{b}_{1}$ & & $\mathrm{~b}_{2}$ & $\mathrm{~b}_{3}$ & $\mathrm{~b}_{4}$ & $\mathrm{~b}_{5}$ & $\mathrm{~b}_{6}$ & $\mathrm{~b}_{7}$ & $\mathrm{~b}_{8}$ & $\mathrm{~b}_{9}$ & $\mathrm{~b}_{10}$ \\
\hline 0,1 & & 5,7 & 0,52 & 4,81 & $-239,8$ & 4,17 & $-41,7$ & 281,5 & 4915 & -313314 \\
\hline & $\mathrm{a}$ & \multicolumn{2}{|c|}{$\mathrm{c}_{1}$} & $\mathrm{c}_{2}$ & $\mathrm{c}_{3}$ & $\mathrm{c}_{4}$ & $\mathrm{c}_{5}$ & $\mathrm{c}_{6}$ \\
\hline & 38 & \multicolumn{2}{|c|}{15} & 5 & 28 & 0,5 & 0,5 & 0,25 \\
\hline
\end{tabular}

Like any other dependence, the obtained "cooling" function of $\operatorname{air} \Delta T_{\mathrm{x}}=f\left(\bar{L} ; \mu ; p_{i n} ; D_{T} ; \overline{D_{\mathrm{D}}} ; \overline{d_{\mathrm{eq}}}\right)$ can be reliably used in a certain range of values. The range of values of the function variables is given in Table 2.

Table 2. Range of application of the formula (7) for calculation $\Delta T_{\mathrm{x}}$.

\begin{tabular}{|c|c|c|c|c|c|}
\hline $\bar{L}$ & $p_{\text {in }}$, МПа & $D_{T}$, мм & $\overline{D_{D}}$ & $\mu$ & $\overline{d_{\text {eq }}}$ \\
\hline $10 \ldots 25$ & $0,3 \ldots 0,6$ & $10 \ldots 30$ & $0,413 \ldots 0,715$ & $0,3 \ldots 0,8$ & $0,228 \ldots 0,28$ \\
\hline
\end{tabular}

The dependence (7) showed the greatest convergence with the empirical technique given in [1]. By this method, the basic geometric parameters of the vortex tube for cooling the object with heat release up to $1 \mathrm{~kW}$ :

- $\quad$ diameter of the vortex tube $17.9 \mathrm{~mm}$;

- the height and width of the nozzle should be $3.5 \mathrm{~mm}$ and $7 \mathrm{~mm}$;

- diameter of the aperture $9.6 \mathrm{~mm}$;

- length of the vortex tube is not less than $161,1 \mathrm{Mm}$

\section{DEVELOPMENTS OF CONSTRUCTION AND INTRODUCTION TO PRODUCTION}

Based on the obtained parameters, the design of the product was developed in the form of a 3D model, shown in Fig. 2. In this figure, we can see a vortex tube 1 with a tangential gas supply through a collet with a throttle 3 , adjusting the temperature and flow of cold and hot flow with Using the handle 2 and the poly-hinge tube 4 to feed the jet into the cutting zone.

The construction comprises the following features:

1. Reliability due to the absence of moving elements during operation;

2. Ease of connection to a pneumatic system through standard factory fitting compound;

3. Convenient supply of cold air to the cutting area through a poly-hose tube;

4. Wideadjustmentrange.

According to the developed 3D models of individual parts and assembly of the vortex tube, drawings were made. In the metal, this design was implemented in the tool shop of JSC «Salut», since the choke 3 (Figure 2) was equipped with a fitting clamp of a standard pneumatic tube, the connection to the factory compressor station did not cause any difficulties. The temperature and the ratio of the hot and cold flow were adjusted freely with the help of the handle 2. Moreover, with a considerable opening of the throttle, the tube operated as a vacuum pump, that is, air was sucked through the 
polycharne tube 4 . When the choke 2 was compressed, a flow separation was observed, and through the poly- "Cooled" air, and through the throttle 2 heated.

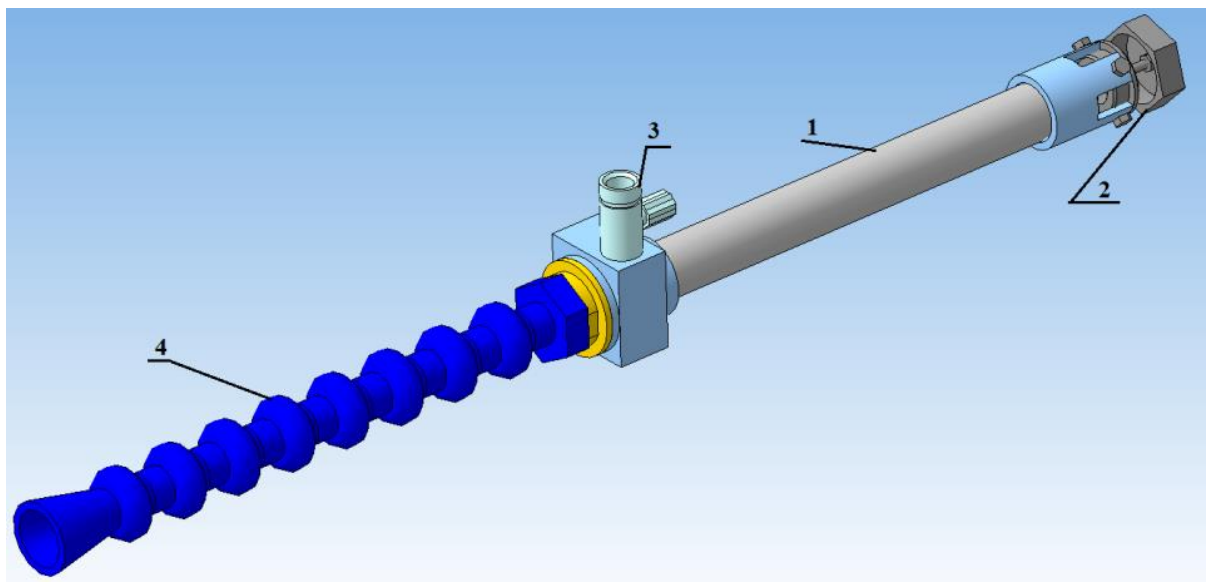

Figure 2. Designed construction.

The air temperature and pressure in the compressor station were measured in automatic mode and displayed. During the experiment, the pressure was $0.67 \mathrm{MPa}$, the temperature was $98^{\circ} \mathrm{C}\left(T_{\text {in }}\right)$. Thus, the product was tested in hot enough air, which contained moisture. Temperature measurements were made in the range of $\mu$ from 0.4 to 0.8 using a chromel-alumel thermocouple (TXA). The experimental dependence of the cooling effect on the flow coefficient is shown in Fig. 3.

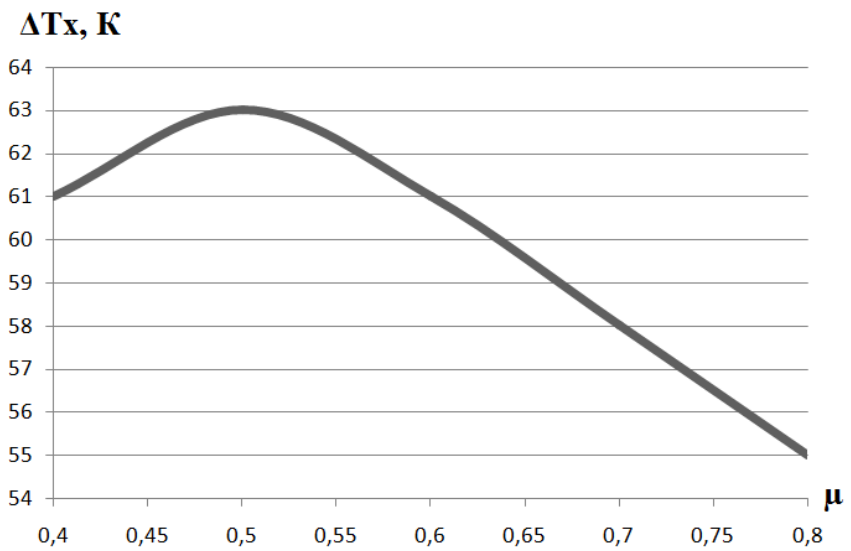

Figure 3. Dependence of the cooling effect on the flow coefficient.

The introduction into production was carried out on the turning of a very whimsical to the thermal processes of the structural material - aluminum alloy AL4. When machined, this material tends to stick to the chip. This process limits the cutting modes. After installing the vortex tube on the machine, the machine operator was able to increase the feed of the cutter from $0.6 \mathrm{~mm} / \mathrm{rev}$ to $1 \mathrm{~mm} / \mathrm{rev}$ for the same depth of cut and spindle speed. The morphology of the chips did not change at the same time. Thus, the introduction of a vortex cooler made it possible to reduce the labor intensity of the operation by a factor of 1.7 .

\section{CONCLUSION}


A formula for determining the effect of air cooling by a vortex tube is proposed and justified, depending on the geometric parameters of the device and the parameters of the input flow. With its help, the design of an air cooling system for the cutting zone for aerospace materials has been developed and implemented. This device was introduced into production at JSC "Salut.

\section{REFERENCES}

1. Merkulov A.P. Vortex effect and its application in engineering Izd. 2nd revision. and additional. Samara, Optima. (1997)

2. Martynov A.V. Borodyansky V.M. What is a vortex tube (Energy,1976)

3. Tarnapolsky A.V. Vortex heat and power devices. Penza: Publishing house of the state. University, (2007)

4. PiralashviliSh.A., Polyaev VM and others. The vortex effect. Experiment, theory, technical solutions(UNPTs "Energomash", 2000)

5. Suslov A.D., Ivanov S.V. and others. Vortex devices.(Mechanical Engineering, 1985)

6. GOST 22616-77. Pipes are swirling. Terms and Definitions.

7. Barbonov, EO, Biryuk, VV, Gaynullin, MN, Sotova, VA, Chertykovtsev, PA Hybrid cooling system for on-board IR receivers based on vortex and thermoelectric effects(Bulletin of the International Academy of Refrigeration№ 2, 2017) 